\title{
Quality of Life Determinants in Professional Athletes
}

\section{Paweł F Nowak (iD) \\ Cezary Kuśnierz' \\ Dariusz Bajkowski}

'Faculty of Physical Education and Physiotherapy, Opole University of Technology, Opole, Poland; ${ }^{2}$ KIME Martial Art School in Warsaw, Warsaw, Poland
Correspondence: Paweł F Nowak Faculty of Physical Education and Physiotherapy, Opole University of Technology, ul Prószkowska 76, Opole, 45-758, Poland

Tel +48774498267

Email p.nowak@po.edu.pl
Background: The study attempted to answer the question of whether the type of practiced sport (individual, team) is a determinant of quality of life in athletes. The study was also intended to identify the best quality of life determinants in professional karate practitioners and team sports players from among such socio-cultural factors as age, gender, marital status, material situation, level of education, and types of health behaviors.

Methods: The study involved 110 Polish players of team sports and 90 martial arts practitioners. All competitors had high sporting achievements. A Paper-and-Pen Interview questionnaire was used as a standardized survey method. The Inventory of Health Behaviors was used to evaluate respondents' health behaviors. The Comprehensive Quality of Life Scale was used to measure the quality of life in its objective and subjective components.

Results: Among the predictors of quality of life, only three proved to be statistically significant: proper dietary habits $(\beta=0.204)$, positive mental attitude $(\beta=0.283)$ and athletes' gender $(\beta=0.191)$. It turns out that men are statistically more likely to achieve a higher quality of life than women. The type of practiced sport did not turn out to be a quality of life determinant.

Conclusion: The type of practiced sport is not a significant quality of life predictor, perhaps because high-level sports activities are professional in nature, which makes the professional and sports activities uniform. The results of the study may suggest that the determinants of the quality of life of professional athletes are found in their personality rather than solely in their socio-cultural environment. Finally, studies of determinants of athletes' quality of life can help develop optimal strategies for improving the quality of life in society in general; however, in-depth qualitative research also seems to be necessary to do it.

Keywords: quality of life, professional athletes, health behaviors

\section{Background}

In the context of the development of many mental health problems, including depression, finding ways to improve quality of life has become a cultural challenge in countries with high or satisfactory economic standards. ${ }^{1}$ One of the improvement strategies can be increased sporting activity, which may not only provide viewers with entertainment and enjoyment but also give practitioners feelings of success, joy, community, or a sense of life. Sporting passions, goals and aspirations that trigger motivation to work on oneself help people to achieve their physical and psychosocial well-being. ${ }^{2,3}$ Commercialization of modern sport allows the best athletes to make a living from their passion. However, the professionalization of sporting activities also entails a number of negative consequences specific to professional work, which may endanger the maintaining of a high quality of life. ${ }^{4-6}$ 
The concept of quality of life has become popular from the perspective of social, economic and cultural development, but so far, no flawless definition of quality of life, applicable in interdisciplinary research, has been formulated. ${ }^{7}$ Quality of life is associated with a sense of life satisfaction and contentment with life progress, individual achievements, perspectives, perception of one's own potentials and resources found in the social, cultural, or physical environment. ${ }^{8}$ According to Cummins, ${ }^{9}$ quality of life is a psychological state representing an aggregate measurement of seven domains of life satisfaction: material well-being, emotional well-being, productivity, intimacy, safety, community and health. Cummins et $\mathrm{al}^{10}$ proposed a model of subjective well-being homeostasis, which includes cognitive and emotional components, whose measurement allows the assessment of subjective quality of life. The model assumes two potential pathways involving the perception of met and unmet needs, which describe the relationships between the objective circumstances of life and perceived well-being. It focuses on a homeostatic system against environmental challenges. Individuals strive to maintain a constant level of life satisfaction, and well-being is controlled by personality and cognitive buffers that maintain a relatively constant balance, ie the level of life satisfaction. In the Western European population, the average life satisfaction rate amounts to $75 / 100$ points. ${ }^{11}$ The theoretical construct described above, which assumes the recognition of environmental challenges, may be helpful in considering the quality of life of professional athletes.

Research shows that physically active people, including professional athletes, enjoy higher quality of life levels than non-training people. ${ }^{12-15}$ This is reflected in many aspects of life such as physical functioning, general health perception, social functioning, and mental health. ${ }^{16}$ The positive impact of physical activity on the quality of life is also confirmed by authors of physical exercise programs used for treatment of depression and anxiety states, not only because of the involved release of endorphins but also interactions with other people, which is particularly evident in team sports. ${ }^{15}$ It has even been proven that the level of sports advancement significantly affects the quality of life and is higher in professionals. Modolo et $\mathrm{al}^{17}$ suggest that a higher frequency and volume of training, ie a significant feature of professional sport, can have a significant impact on one's quality of life. Physical fitness was also shown to be strongly correlated with better quality of life. ${ }^{18}$ Also, the length of training experience of athletes is associated with increasing levels of life satisfaction, inner peace, sense of security, or personal success. ${ }^{15}$

Numerous studies concerning quality of life and its determinants have been conducted to date on groups of people affected by various physical dysfunctions, diseases, and psychosocial problems. Professional athletes are considered to be healthy people, living out of their own passion, and associated with success. Therefore, it is commonly assumed that their level of mental well-being is high, and they are often subjected to fulfilling the function of role models. However, athletes with a high level of sportsmanship function in a highly stressful environment. Extreme training loads often lead to mental exhaustion, increase professional stress, and reduce quality of life. ${ }^{19,20}$ Professional athletes are expected not only to propagate a particular sport but also a socially desirable, goaloriented, active lifestyle. Many educators recognize the enormous educational potential of professional athletes and thus emphasize the development of Olympic education programs. ${ }^{21}$ From the point of view of public health it is worthwhile to study elite athlete groups with a great power and range of social impact, who are opinion leaders, trendsetters, and ambassadors of such values as health, success, and good quality of life. This can help in designing effective educational interventions.

The study attempted to answer the question of whether the type of practiced sport (individual, team) is a determinant of quality of life in athletes.

We hypothesized that such differentiation did occur because different types of sports require different personality profiles. The presence of a combination of extraversion and neuroticism has a significant impact on quality of life. ${ }^{10,22}$ Previous research has shown that the levels of neuroticism differ between athletes representing individual and team sports. Team sports are preferred by emotionally labile people since team activities involve fewer resources, are safer for them, and the mental load is distributed among team members. Thus, team players are more neurotic than individual athletes. Although the level of extraversion in athletes is generally high, it is higher in representatives of team sports. ${ }^{23}$

The intention was also to identify the best quality of life determinants in professional karate practitioners and team sports players from among such socio-cultural factors as age, gender, marital status, material situation, level of education, and types of health behaviors. It can be assumed that all the above factors are significant predictors of quality of life, but with varying degrees of intensity. It 
is worthwhile to explore the internal structure of the quality of life construct under study.

\section{Methods}

\section{Participants}

The study involved 110 Polish team sports players and 90 martial arts practitioners. The sample selection was purposive and accounted for the athletes' experience level. All competitors had high sporting achievements - there professional sportsmen were able to gain a high salary for this activity. The group of sports team players consisted of players from three top-tier Polish divisions of handball, football, volleyball, and basketball, ie Top league, I league, and II league. The martial arts group comprised 90 Kyokushin and Shotokan karate competitors, most of whom were dan-ranked from 1 to 7. The majority of respondents were men (team sport players $-68.1 \%$, martial arts practitioners $-74.4 \%$ ) and single (team sport players - $80.9 \%$, martial arts practitioners $52.2 \%$ ). The average age of karate practitioners was 34.67 years, and of team sport players - 23.84 years.

All respondents were informed about the purpose and course of the study and consented to take part in it. All research activities were reviewed and approved by Opole University of Technology Research Ethics Committee. This study complies with the Declaration of Helsinki. Written informed consent was obtained from participants prior to the study commencement.

\section{Measures}

A Paper-and-Pen Interview (PAPI) questionnaire was used as a survey method.

The Inventory of Health Behaviors (IHB) ${ }^{24}$ was used to evaluate respondents' health behaviors. It consists of 24 statements describing different types of health behaviors which, depending on their frequency, are assigned a value on a 5-point Likert scale. Based on the collected data, an index of overall intensity of health behaviors as well as indices for four individual categories of health behaviors, ie proper dietary habits ( $\mathrm{PDH})$, prophylactic behaviors (PB), positive mental attitude (PMA), and health practices (HP) were calculated - IHB as total points of all statements and above, in each of four categories, as a sum of relevant six statements divided by six.

The internal consistency index value Cronbach's alpha for the health behaviors scale (HBI) was $\alpha=0.861$ and for particular scales: PDH (0.789), PB (0.601), PMA (0.710), HP (0.512). The author of the research tool states (for HBI $\alpha=0.85$ and for particular scales $0.60-0.65$ ). Following the recommendations of the inventory author, the general health behavior index was converted to sten scores, with 1-4 sten scores interpreted as low, 5-6 sten scores as average, and 7-10 sten scores as high.

The Comprehensive Quality of Life Scale by R. A. Cummins ${ }^{25}$ was used 14 items to measure the quality of life in its objective and subjective components, covering seven domains: material well-being, health, productivity, intimacy, safety, community and emotional well-being. The respondents first assessed the validity of the domains in the form of statements on a scale from 1 to 5 , and then determined the level of their satisfaction with them on a scale from 1 to 7 . The measurement of each objective domain is achieved by obtaining an aggregate importance score based on the measurement of three objective indices relevant to that domain. The measurement of each subjective domain is achieved by obtaining a satisfaction score for that domain, whose relevance is weighted by the perceived importance of the domain for an individual. The internal consistency indicator for the whole scale was $\alpha=0.790$. The author of the research tool states that for the purpose of evaluating Quality of Life Scale sub-scale alphas will be sought in the range 0.3 to 0.7 .

All indicators were calculated in accordance with instructions of research tools.

\section{Statistical Analysis}

The collected data were statistically analyzed using the Statistica 13 software package. Descriptive statistics were calculated. Tested variables were normally distributed. Single multivariate linear regression analysis was used for the study. The assumptions used in the single multivariate linear regression analysis were - linear dependence of variables, a suitable number of observations, normality of the residual distribution and homoscedasticity.

The non-parametric Mann-Whitney $U$-test was used to assess the significance of differences between the variables, and correlations between the variables were calculated using Spearman's rank correlation coefficient. The level of statistical significance was set at $p<0.05$ for all computations.

\section{Results}

Age is a factor significantly differentiating the studied athletes $(p<0.05)$ both by sex (Table 1$)$ and type of practiced sport. The average age in the group of professional team players was 23.84 years, $S D=5.83$ while in 
Table I Analyzed Variables in Different Groups of Athletes

\begin{tabular}{|c|c|c|c|c|c|c|c|}
\hline Variable & Group of Athletes & $\overline{\mathbf{X}}$ & sd & me & $q$ & $\mathbf{z}$ & $p$ \\
\hline \multirow[t]{2}{*}{ Age } & Women & 25.12 & 8.15 & 24.00 & 5.00 & -2.18 & $0.029 *$ \\
\hline & Men & 30.19 & 13.01 & 24.00 & 8.50 & & \\
\hline \multirow[t]{2}{*}{ Education } & Women & 2.20 & 0.74 & 2.00 & 0.50 & -0.06 & 0.948 \\
\hline & Men & 2.24 & 0.56 & 2.00 & 0.50 & & \\
\hline \multirow[t]{2}{*}{ Financial situation } & Women & 1.75 & 0.75 & 2.00 & 0.50 & -0.53 & 0.594 \\
\hline & Men & $\mathrm{I} .78$ & 0.59 & 2.00 & 0.50 & & \\
\hline \multirow[t]{2}{*}{ Overall quality of life } & Women & 8.65 & 3.91 & 8.57 & 2.64 & -3.30 & $0.009 *$ \\
\hline & Men & 10.59 & 3.91 & 11.42 & 2.35 & & \\
\hline \multirow[t]{2}{*}{ Emotional well-being } & Women & 9.58 & 8.37 & 10.00 & 5.00 & -1.85 & 0.063 \\
\hline & Men & 12.29 & 5.87 & 12.00 & 2.50 & & \\
\hline \multirow[t]{2}{*}{ Community } & Women & 8.62 & 6.59 & 8.00 & 3.00 & 2.45 & $0.014^{*}$ \\
\hline & Men & 6.73 & 5.92 & 6.00 & 4.50 & & \\
\hline \multirow[t]{2}{*}{ Safety } & Women & 10.32 & 6.65 & 10.00 & 4.50 & -2.13 & $0.033^{*}$ \\
\hline & Men & 12.52 & 5.40 & 12.00 & 2.50 & & \\
\hline \multirow[t]{2}{*}{ Intimacy } & Women & 9.91 & 6.59 & 10.00 & 5.00 & -4.41 & $0.000 *$ \\
\hline & Men & 14.23 & 5.96 & 15.00 & 5.00 & & \\
\hline \multirow[t]{2}{*}{ Productivity } & Women & 9.91 & 6.82 & 6.00 & 4.00 & -1.76 & 0.077 \\
\hline & Men & 8.50 & 6.75 & 8.00 & 3.00 & & \\
\hline \multirow[t]{2}{*}{ Health } & Women & 8.56 & 6.67 & 9.50 & 5.00 & -4.12 & $0.000 *$ \\
\hline & Men & 12.67 & 5.75 & 15.00 & 2.50 & & \\
\hline \multirow[t]{2}{*}{ Material well-being } & Women & 6.60 & 5.22 & 6.00 & 3.00 & -0.72 & 0.468 \\
\hline & Men & 7.17 & 4.63 & 8.00 & 2.00 & & \\
\hline \multirow[t]{2}{*}{ IHB } & Women & 84.24 & 13.19 & 85.00 & 6.50 & 0.88 & 0.377 \\
\hline & Men & 83.28 & 11.86 & 83.50 & 7.50 & & \\
\hline \multirow[t]{2}{*}{$\mathrm{PDH}$} & Women & 3.56 & 0.69 & 3.66 & 0.33 & 2.01 & $0.043 *$ \\
\hline & Men & 3.40 & 0.68 & 3.50 & 0.41 & & \\
\hline \multirow[t]{2}{*}{ PB } & Women & 3.51 & 0.63 & 3.50 & 0.50 & 1.77 & 0.075 \\
\hline & Men & 3.33 & 0.65 & 3.33 & 0.50 & & \\
\hline \multirow[t]{2}{*}{ PMA } & Women & 3.50 & 0.68 & 3.58 & 0.41 & -2.50 & $0.012^{*}$ \\
\hline & Men & 3.76 & 0.58 & 3.83 & 0.33 & & \\
\hline \multirow[t]{2}{*}{ HP } & Women & 3.45 & 0.61 & 3.66 & 0.41 & 1.50 & 0.132 \\
\hline & Men & 3.37 & 0.57 & 3.33 & 0.41 & & \\
\hline & & & & & & & \\
\hline \multirow[t]{4}{*}{ Gender } & Individual sports & \multicolumn{2}{|c|}{ Women } & \multicolumn{2}{|c|}{23} & \multicolumn{2}{|c|}{25.56} \\
\hline & & \multicolumn{2}{|c|}{ Men } & \multicolumn{2}{|c|}{67} & \multicolumn{2}{|c|}{74.44} \\
\hline & Team sports & \multicolumn{2}{|c|}{ Women } & & & & \\
\hline & & & & & & & \\
\hline Marital status & Individual sports & & & & & & \\
\hline & & & & & & & \\
\hline & Team sports & & & & & & \\
\hline & & & & & & & \\
\hline
\end{tabular}

Abbreviations: $\bar{x}$, arithmetic mean; SD, standard deviation; Me, median; Q, quartile deviation; Z, Mann-Whitney U-test for $\mathrm{n}>20$; $\mathrm{p}$, probability value (statistically significant at $\mathrm{p} \leq 0.05$ a symbol $(*))$; IHB, The Inventory of Health Behaviors; PDH, proper dietary habits; PB, prophylactic behaviors; PMA, positive mental attitude; HP, Health practices. 
the group of karate practitioners - 34.67 years, $S D=14.69$ $(Z=4.84 ; p<0.001)$. The observed significant difference reflects the specificity of career development in different sports. In the group of martial arts practitioners, a slightly higher average education-level variable was also found (individual sports $M=2.35 ; S D=0.67$, team sports players $M=2.13 ; S D=0.54 ; \mathrm{Z}=2.45 ; p<0.05)$. There were no other differences with regard to the type of practiced sport.

Gender is a factor significantly differentiating the respondents in terms of the analyzed variables. Men scored higher in overall quality of life and in quality of life domains, such as health, intimacy, and safety. Women, on the other hand, obtained a higher score in the quality of life domain of community.

Most of the surveyed male athletes (48.59\%) are characterized by an average level of health behaviors; a high level was found in $38.03 \%$, and a low level in $13.38 \%$ of male athletes. On the other hand, in the group of female athletes, a low level of health behaviors was found in $24.14 \%$, and a high level in $29.31 \%$ of respondents.

Although there was no significant difference between women and men with respect to the overall health behavior score, statistically significant differences were found for two out of four studied health behavior categories, ie proper dietary habits $(\mathrm{PDH})$ and positive mental attitude (PMA) $(p<0.05)$. Women were characterized by a higher level of PDH, and men by a higher level of PMA (Table 1).

The overall quality of life is positively correlated with all its domains (Tables 2 and 3) In women, the strongest correlation was noted with emotional well-being $\left(r_{s}=0.721\right)$ (Table 2), and the weakest with health $\left(r_{s}=0.344\right)$; while in men the strongest correlation was with productivity $\left(r_{s}=0.769\right)$ and the weakest with community $\left(r_{s}=0.574\right)$ (Table 3 ).

A single multivariate linear regression analysis was carried out (Figure 1). The assumed model, taking into account such variables that are related to the quality of life, such as type of sport, age, gender, marital status, education, financial situation, or health behaviors (PMA, PDH, PB, HP), proved to be statistically significant. The coefficient of determination explained $24 \%$ of the dependent variable of the overall quality of life $\left(R^{2}=0.245 ; d f=11 ; F=5.573 ; p=0.000\right)$. However, among the predictors of quality of life only three proved to be statistically significant: $\mathrm{PDH}(\mathrm{B}=0.181 ; \beta=0.204 ; t=2.423$; $p=0.0163 ;[-95 \% \quad \mathrm{CI}=0.219 ;+95 \% \quad \mathrm{CI}=2.143])$, PMA

Table 2 Correlations Between Individual Quality of Life Domains in Female Athletes

\begin{tabular}{|c|c|c|c|c|c|c|c|c|}
\hline \multicolumn{2}{|c|}{ Variables } & 2. & 3. & 4. & 5. & 6. & 7. & 8. \\
\hline I. & Material well-being & 0.016 & 0.234 & 0.004 & 0.195 & $0.583 *$ & 0.154 & $0.505^{*}$ \\
\hline 2. & Health & & $0.284 *$ & 0.197 & 0.248 & -0.226 & 0.149 & $0.344^{*}$ \\
\hline 3. & Productivity & & & $0.319 *$ & 0.226 & $0.294 *$ & $0.279 *$ & $0.616^{*}$ \\
\hline 4. & Intimacy & & & & $0.569 *$ & 0.041 & $0.45 I^{*}$ & $0.642^{*}$ \\
\hline 5. & Safety & & & & & 0.136 & $0.338^{*}$ & $0.658^{*}$ \\
\hline 6. & Community & & & & & & 0.145 & $0.415^{*}$ \\
\hline 7. & Emotional well-being & & & & & & & $0.70 I^{*}$ \\
\hline 8. & Overall quality of life & & & & & & & \\
\hline
\end{tabular}

Note: $*$ Statistical significant at $p<0.05$.

Table 3 Correlations Between Individual Quality of Life Domains in Male Athletes

\begin{tabular}{|c|c|c|c|c|c|c|c|c|}
\hline \multicolumn{2}{|c|}{ variables } & 2. & 3. & 4. & 5. & 6. & 7. & 8. \\
\hline I. & Material well-being & $0.33 I^{*}$ & $0.434^{*}$ & $0.235^{*}$ & $0.358^{*}$ & $0.183^{*}$ & $0.346 *$ & $0.580 *$ \\
\hline 2. & Health & & $0.446 *$ & $0.380 *$ & $0.486 *$ & 0.158 & 0.505 & $0.68 I^{*}$ \\
\hline 3. & Productivity & & & $0.362^{*}$ & $0.345^{*}$ & $0.458^{*}$ & $0.435^{*}$ & $0.769 *$ \\
\hline 4. & Intimacy & & & & $0.400 *$ & $0.266 *$ & $0.479 *$ & $0.63 I^{*}$ \\
\hline 5. & Safety & & & & & $0.240 *$ & $0.57 I^{*}$ & $0.678^{*}$ \\
\hline 6. & Community & & & & & & $0.263^{*}$ & $0.574^{*}$ \\
\hline 7. & Emotional well-being & & & & & & & $0.721^{*}$ \\
\hline 8. & Overall quality of life & & & & & & & \\
\hline
\end{tabular}

Note: *Statistical significant at $p<0.05$. 


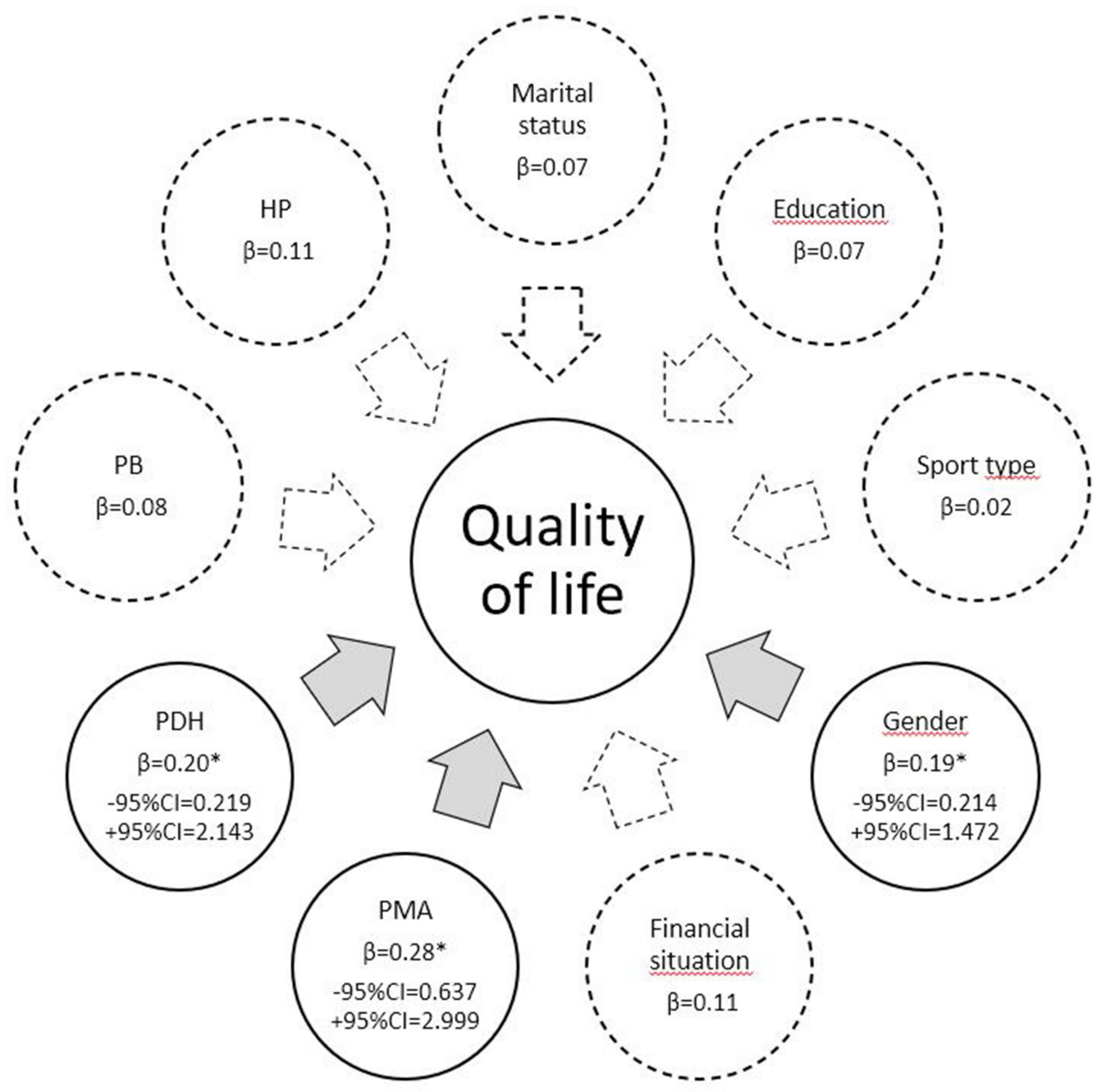

Figure I Assumed quality of life research model with the dependent variable of overall quality of life. Note: *Statistical significant at $p<0.05$.

$(\mathrm{B}=0.814 ; \beta=0.283 ; t=3.040 ; p=0.002 ;[-95 \% \mathrm{CI}=0.637$; $+95 \% \mathrm{CI}=2.999])$ and athletes' gender $(\mathrm{B}=0.843 ; \beta=0.191$; $t=2.646 ; p=0.008 ;[-95 \% \mathrm{CI}=0.214 ;+95 \% \mathrm{CI}=1.472])$. It turned out that men are statistically more likely to achieve a higher quality of life than women. The type of practiced sport did not turn out to be a quality of life determinant.

\section{Discussion}

The purpose of this study was intended to identify quality of life determinants in karate practitioners and team sports players from among such socio-cultural variables as age, gender, marital status, financial situation, education, and types of health behaviors. Quality of life is a complex construct, and all its determinants are rather difficult to establish and, above all, to estimate. ${ }^{26}$ Most of them, however, can be grouped into several basic categories: genetic, psychological, social, and economic. ${ }^{27-30}$ All these categories of quality of life determinants are represented in present-day competitive sport. Preselection in sport accounts for candidates' genetic and psychological predispositions affecting sporting success and thus the socio-cultural and economic development of the individual.

Sporting activity is manifested by a great diversity of competition types, conditions, and rules of practice. In the present study, athletes representing two different types of sport competition, ie individual and team sports, were analyzed. According to Veenhoven, ${ }^{31}$ individualization in society improves quality of life. However, in the present study, this distinction has not proven to have a significant connection with the quality of life of athletes. Athletes representing different sports can achieve the same high level of life satisfaction but in different ways: in individual sports from their relationship with the environment, and in team sports through their relationship with another person.

In our model, athletes' gender proved to be an important predictor of quality of life. Men achieved a better, 
significantly differentiated, quality of life score, corresponding with the results of Tanabe et $\mathrm{al}^{32}$ who have shown that female athletes have lower psychological wellbeing than male athletes and Padrão dos Santos, ${ }^{14}$ whose results suggest that the quality of life in the family domain is more satisfying for males than for females.

In the US population, the lower quality of life of women is explained by sociodemographic differences, in particular, by the socioeconomic variation in selfesteem. ${ }^{13,33}$ Perhaps, the existing gender inequalities in the world of sport have a similar effect on the obtained results. According to Smith and Stewart, ${ }^{34}$ sport is still a male domain, and female athletes' careers are somewhat different due to the different culturally established roles of women in a society determined by motherhood.

In the present study, financial situation was not a significant quality of life determinant. Material well-being was not a dominant feature of the overall quality of life score either. Numerous studies indicate that although socioeconomic status is associated with a better quality of life for Poles, it is not a dominant determinant and guarantee of happiness and life satisfaction. ${ }^{35}$ It can also be assumed that the surveyed athletes, especially those representing the martial arts, are not characterized by a purely hedonistic approach, but rather demonstrate an eudaimonic orientation in their lives. ${ }^{36}$

Undoubtedly, modern professional sport generates business values but it should also focus on developing social values. It is extremely important to maintain an appropriate balance in this respect. ${ }^{37}$ It should not be forgotten that professional sport is, however, a highly specific business activity and, as Smith and Stewart ${ }^{34}$ note, requires a specific approach as it has both commercial and cultural dimensions. This can generate many social benefits for a number of parties involved in sport. Successful sport practitioners are assured of a high level of social status, but not always economic. The latter depends on the type of sport, its mediality, and popularity. Combat sports and martial arts, and especially karate - as in this study, do not offer a business product with such mass spectacular potential as popular team games (football, volleyball, basketball). This often happens, even despite objectively more prestigious sporting successes of athletes in some niche sports. However, sports with both smaller and greater commercially potential can provide space for satisfying experiences for practitioners and thus support their quality of life.

Healthy behaviors are important for improving quality of life. Ge et $\mathrm{al}^{38}$ proved that increasing physical activity and promoting adequate sleep duration is a key health promotion strategy dedicated to young people. Researchers stress that sport can be responsible not only for physical well-being, but it also has a great potential for socialisation and contributes to solving problems and improving quality of life, therefore young people should be encouraged to engage in extracurricular sports activities. ${ }^{39}$ Professionalism in sport requires practicing pro-healthy behaviors. Appropriate diet, sleep duration, and constructive stress management are necessary to achieve good sporting results. ${ }^{40}$ In a wellorganized training process, athletes receive support from many specialists. Education in this area is also very important. ${ }^{41}$ In the tested regression model, significant quality of life determinants included not only proper dietary habits but also a positive mental attitude. Most studies indicate a positive correlation between optimism and sports performance. ${ }^{42}$ A well-organized training process is aimed not only at developing physical fitness but also at strengthening the mental potential of athletes, which is indispensable in both sport competition and training.

A limitation of this study was the size of the research sample. A specific difficulty was also its selection, taking into account the great variety of events and competitions within individual or team sports. Not all sports are popular enough to ensure their respective stars a high level of media recognition and, consequently, the realization of a specific lifestyle. Not all professional athletes function in pop culture with a celebrity status that engenders not only sports fans but also followers of their non-sports lives, which can undoubtedly affect the overall quality of life assessment. A high sporting level is an individual characteristic that hardly yields statistical quantitative studies. It would certainly be valuable to enhance the research strategy with qualitative research methods. In the presented research model for statistical analyses, many variables were not included eg BMI, previous injury, current pain, etc. that could potentially influence the results.

\section{Conclusions}

The type of practiced sport is not a significant quality of life predictor, perhaps because high-level sports activities are professional in nature, which makes the professional and sports activities uniform. Further research into the quality of life of athletes should take into account their successes and failures, ie their career paths as well as many other intermediary variables. The results of the study may suggest that the determinants of the quality of life of professional athletes are found in their personality rather than solely in their socio-cultural environment. Finally, studies of determinants of athletes' quality of life 
can help develop optimal strategies for improving the quality of life in society in general; however, in-depth qualitative research also seems to be necessary to do it.

\section{Acknowledgments}

The authors gratefully acknowledge the support of Idokan Poland Association.

\section{Disclosure}

The authors report no conflicts of interest in this work.

\section{References}

1. Abdel-Hadi A. Culture, quality of life, globalization and beyond. Procedia Soc Behav Sci. 2012;50:11-19. doi:10.1016/j. sbspro.2012.08.011

2. Cerulli C, Parisi A, Sacchetti M, et al. Dancing with health: a new dance protocol to improve the quality of life of breast cancer survivors. Medicina dello Sport. 2019;72(2):295-304. doi:10.23736/ S0025-7826.19.03530-0

3. Pašková L, Sližik M, Blahutková M, Górny MP, Benedik L. Sport activity in the context of subjective well-being of university students. Trends Sport Sci. 2019;26(2):85-90. doi:10.23829/TSS.2019.26.2-7

4. Babic V, Bjelic G, Bosnar K. Life well-being and reasons for the termination of sport careers among Croatian elite athletes. Sport Mont. 2019;17(3):21-25. doi:10.26773/smj.191008

5. Filbay S, Pandya T, Thomas B, McKay C, Adams J, Arden N. Quality of life and life satisfaction in former athletes: a systematic review and meta-analysis. Sports Med. 2019;49(11):1723-1738. doi:10.1007/s40279-019-01163-0

6. Onate J. Depression in ultra-endurance athletes, a review and recommendations. Sports Med Arthrosc Rev. 2019;27(1):31-34. doi:10.1097/JSA.0000000000000233

7. Trzebiatowski J. Quality of life in the perspective of social and medical sciences - classification of definitions. Hyg Pub Health. 2011;46:25-31.

8. Gałuszka A. Physical activity and quality of life of women - comparative analysis of selected psychological aspects. Humanum. 2017;25(2):87-100.

9. Cummins RA. The domain of life satisfaction: an attempt to order chaos. Soc Indic Res. 1996;38:303-328. doi:10.1007/BF00292050

10. Cummins RA, Gullone E, Lau ALD. A model of subjective wellbeing homeostasis: the role of personality. In: Gullone E, Cummins RA, editors. The Universality of Subjective Wellbeing Indicators. Dordrecht: Kluwer Academic; 2003:7-46.

11. Cummins RA, Eckersley R, Pallant J, VanVugt J, Misajon R. Developing a national index of subjective wellbeing: the Australian unity wellbeing index. Soc Indic Res. 2003;64:159-190. doi:10.1023/ A:1024704320683

12. Argyle M, Martin M. The psychological causes of happiness. In: Strack WF, Argyle M, Schwarz N, editors. Subjective Well-Being. Oxford: Pergamon Press; 1991:77-99.

13. Pisinger C, Toft U, Aadahl M, Glümer C, Jørgensen T. The relationship between lifestyle and self-reported health in a general population. The Inter 99 study. Prev Med. 2009;49:418-423. doi:10.1016/j. ypmed.2009.08.011

14. Padrăo Dos Santos AL. Quality of life in professional, semiprofessional, and amateur athletes: an exploratory analysis in Brazil. Sage Open. 2013;1-8. doi:10.1177/2158244013497723
15. Kotarska K, Nowak L, Szark-Eckardt M, Nowak M. Selected healthy behaviors and quality of life in people who practice combat sports and martial arts. Int J Environ Res Public Health. 2019;16(5):875. doi:10.3390/ijerph16050875

16. Snyder AR, Martinez JC, Bay RC, Parsons JT, Sauers EL, Valovich McLeod TC. Health-related quality of life differs between adolescent athletes and adolescent nonathletes. J Sport Rehabil. 2010;19 (3):237-248. doi:10.1123/jsr.19.3.237

17. Modolo VB, Mello MT, Gimenez PRB, Tufik S, Antunes HKM. Physical exercise dependence: mood, quality of life in amateur and professional athletes. Braz J Sport Med. 2009;15:355-359. doi:10.1590/S1517-86922009000600007

18. Daimiel L, Martínez-González MA, Corella D, et al. Physical fitness and physical activity association with cognitive function and quality of life: baseline cross-sectional analysis of the PREDIMED-plus trial. Sci Rep. 2020;10(1):3472. doi:10.1038/s41598-020-59458-6

19. Gouttebarge V, Backx FJG, Aoki H, Kerkhoffs GMM. Symptoms of common mental disorders in professional football (soccer) across five European countries. J Sport Sci Med. 2015;14:811-818.

20. Aleshicheva A. Psychological health of professional athletes involved in extreme sports. Kemerovo State Univ Bull. 2016;67(3):38-44. doi:10.21603/2078-8975-2016-3-38-44

21. Kidd B. Taking the rhetoric seriously: proposals for Olympic education. Quest. 1996;48:82-92. doi:10.1080/00336297.19 96.10484180

22. Francis LJ. Happiness is a thing called stable extraversion: a further examination of the relationship between the Oxford Happiness Inventory and Eysenck dimensional model of personality and gender. Pers Individ Differ. 1998;26:5-11. doi:10.1016/S01918869(98)00185-8

23. Derbis R, Jędrek K. The sense of quality of life and personality of individual and team sportsmens. Przeglad Psychologiczny. 2010;53:9-32.

24. Juczyński Z. Measurement Tools in the Promotion and Health Psychology. Warszawa: Pracownia Testów Psychologicznych; 2009.

25. Cummins RA. Comprehensive Quality of Life Scale-Adult: ComqolA5. Melbourne: School of Psychology, Deakin University; 1997.

26. Bognar G. The concept of quality of life. Soc Theory Pract. 2005;31 (4):561-580. doi:10.5840/soctheorpract200531426

27. Lucas RE, Fujita F. Factors influencing the relation between extraversion and pleasant affect. J Pers Soc Psychol. 2000;79 (6):1039-1056. doi:10.1037/0022-3514.79.6.1039

28. Philips D. Quality of Life. Concept, Policy and Practice. London and New York: Routledge; 2006.

29. Sheldon KM, Lyubomirsky S. Is it possible to become happier? (And if so. how?). Soc Personal Psychol Compass. 2007;1(1):129-145. doi:10.1111/j.1751-9004.2007.00002.x

30. Diener E, Oishi S, Lucas RE. Personality, culture, and subjective well-being: emotional and cognitive evaluations of life. Annu Rev Psychol. 2003;54:403-425. doi:10.1146/annurev.psych.54.1016 01.145056

31. Veenhoven R. Quality-of-life in individualistic society. Soc Indic Res. 1999;48:157-186. doi:10.1023/A:1006923418502

32. Tanabe T, Snyder AR, Bay RC, Mcleod TCV. Representative values of health-related quality of life among female and male adolescent athletes and the impact of gender. Athl Train Sports Health Care. 2010;2:106-113. doi:10.3928/19425864-20100301-01

33. Cherepanov D, Palta M, Fryback DG, Robert SA. Gender differences in health-related quality-of-life are partly explained by sociodemographic and socioeconomic variation between adult men and women in the US: evidence from four US nationally representative data sets. Qual Life Res. 2010;19:1115-1124. doi:10.1007/s11136-010-9673-x

34. Smith ACT, Stewart B. The special features of sport: a critical revisit. Sport Manage Rev. 2010;13:1-13. doi:10.1016/j.smr.2009.07.002 
35. Włodarczyk K. The quality of life perceived by Poles in the $21 \mathrm{st}$ century. Consump Dev. 2015;1(10):3-16.

36. Czapiński J. Meeting of two traditions: hedonism and eudaimonism. In: Czapiński J, editor. Positive Psychology. Learning About Happiness, Health, Strength and Human Virtues. Warsaw: PWN; 2008:13-17.

37. Hills S, Walker M, Barry AE. Sport as a vehicle for health promotion: a shared value example of corporate social responsibility. Sport Manage Rev. 2019;22:126-141. doi:10.1016/j.smr.2018.10.001

38. Ge Y, Xin S, Luan D, et al. Association of physical activity, sedentary time, and sleep duration on the health-related quality of life of college students in Northeast China. Health Qual Life Outcomes. 2019;17 (1):124. doi:10.1186/s12955-019-1194-x

39. Baciu C, Baciu A. Quality of Life and Students' Socialization through Sport. Procedia Soc Behav Sci. 2015;209:78-83. doi:10.1016/j.sbspro.2015.11.260
40. Kerksick CM, Wilborn CD, Roberts MD, et al. ISSN exercise \& sports nutrition review update: research \& recommendations. J Int Soc Sports Nutr. 2018;15:38. doi:10.1186/s12970-018-0242-y

41. Gerbing KK, Thiel A. Handling of medical knowledge in sport: athletes' medical opinions, information seeking behaviours and knowledge sources. Eur J Sport Sci. 2016;16(1):141-148. doi:10.1080/17461391.2014.989278

42. Ortín-Montero FJ, Martínez-Rodríguez A, Reche-García C, Garcés de Los Fayos-ruiz EJ, González-Hernández J. Relationship between optimism and athletic performance. Systematic review. Anales de Psicología. 2018;34(1):153-161. doi:10.6018/analesps.34.1.270351

\section{Publish your work in this journal}

Psychology Research and Behavior Management is an international, peer-reviewed, open access journal focusing on the science of psychology and its application in behavior management to develop improved outcomes in the clinical, educational, sports and business arenas. Specific topics covered in the journal include: Neuroscience, memory and decision making; Behavior modification and management; Clinical applications; Business and sports performance management; Social and developmental studies; Animal studies. The manuscript management system is completely online and includes a very quick and fair peer-review system, which is all easy to use. Visit http://www. dovepress.com/testimonials.php to read real quotes from published authors. 